Supplement of Earth Syst. Dynam., 11, 653-672, 2020

https://doi.org/10.5194/esd-11-653-2020-supplement

(c) Author(s) 2020. This work is distributed under

the Creative Commons Attribution 4.0 License.

(c) (i)
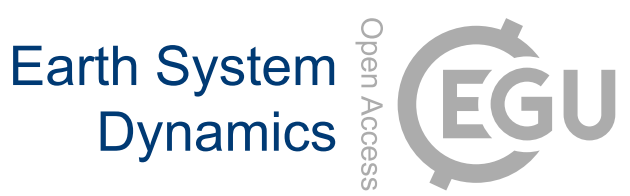

Supplement of

\title{
Mesoscale atmospheric circulation controls of local meteorological elevation gradients on Kersten Glacier near Kilimanjaro summit
}

Thomas Mölg et al.

Correspondence to: Thomas Mölg (thomas.moelg@fau.de)

The copyright of individual parts of the supplement might differ from the CC BY 4.0 License. 


\section{1 | Automated sonic ranger signal detection}

\section{Algorithm}

(a) The algorithm runs with either 1-min (AWS4) or 30-min input (AWS3). It takes advantage of a "reference record" from the first 200 days of measurements at AWS3, when recordings were exceptionally clean (Fig. S1). For the 1-min values the outliers, defined as consecutive height changes greater than two times the standard deviation of the 30-min reference record, are removed first. The 1-min record is then converted into 30-min values by using the 80th percentile of the remaining minute values per half hour.

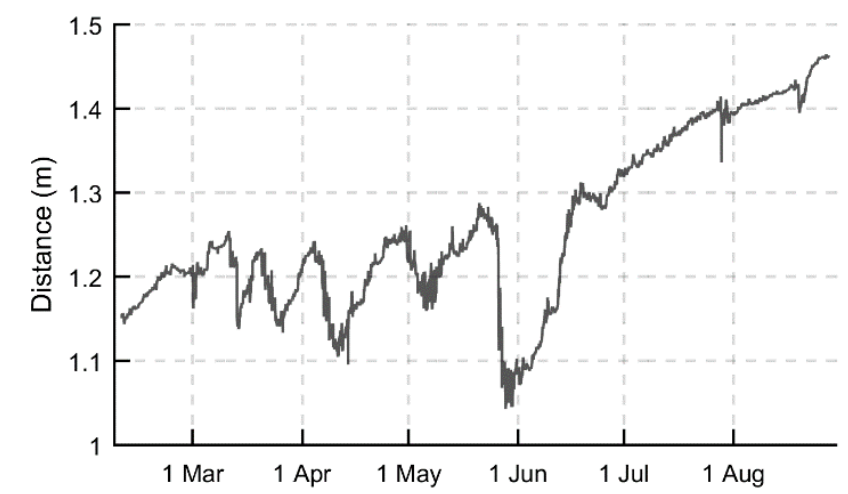

Figure S1: The "reference". Half hourly SR50 record at AWS3 between 9 February and 27 August 2005, shown as distance to the surface.

(b) Standard deviation $(\sigma)$ and mean ( $a$ ) of each day (48 values) are computed for the two records.

(c) A day is subject to correction if (i) its $\sigma$ exceeds a high percentile (PCN-high; here 80th) of the daily standard deviation distribution of the reference record and at the same time, (ii) its maximum halfhourly height change exceeds $\pm 7 \mathrm{~cm}$ or (iii) its half-hourly changes exceed twice $\pm 4 \mathrm{~cm}$ (which is typical for outliers due to a measurement error). The latter ensures that "clean" days with high precipitation over several hours (and thus relatively high $\sigma$ ) are not screened. It also helps retain days with a strong but very short precipitation event (such events are evident in the reference record; these usually feature only one half-hourly change $>4 \mathrm{~cm}$ ).

(d) For each day to correct (according to the steps above), all 30-min values falling outside the day's $a \pm x^{*} \sigma$ range (the "affected" values) are assigned the mean value of the non-affected values. The factor $x$ is linearly interpolated between 0.5 (daily $\sigma=8.5 \mathrm{~cm}$, which is 1.5 times the maximum of daily $\sigma$ in the reference record) and 2 (daily $\sigma=P C N-h i g h=0.8 \mathrm{~cm}$ ), as the correction method should pick up more (less) values on a very (moderately) noisy day. If all 30-min values of a day are affected, missing values (NaNs) are assigned to the entire day.

\section{Calculation of daily and monthly accumulation and ablation}

The height difference between day end and day begin reveals the daily accumulation or ablation. In this regard the midnight value is defined as the mean of all values between 22:00 and 2:00 local time. Such averaging (or employing moving averages for arbitrary times of day) is the standard to smooth the noisy nature of the SR50 sensor (Ryan et al., 2008).

Monthly accumulation (ablation) sums are determined by adding up all daily accumulation (ablation) values. As the correction algorithm produces $\mathrm{NaNs}$ (see above), monthly accumulation (and ablation) is first calculated as a mean from the available daily values $(\mathrm{cm} /$ day), which is then multiplied by the number of days in the respective month. Months with $>7 \mathrm{NaN}$-days are considered to be a month without data in this study. 
Our tests show that the algorithm shows a low sensitivity to the three major parameters: PCN-high, the threshold for the 30-min change (TRH30), the x-range for the definition of the straight line (RANX), and the $y$-range (RANY). We still ran the algorithm with a second parameter combination and consider the resultant difference in the uncertainty estimate (Section 3 below). Parameter Combination 1 employs the values given above $(\mathrm{PCN}-\mathrm{high}=80 \mathrm{th} ; \operatorname{TRH} 30=4 \mathrm{~cm} ; \operatorname{RANX}=[0.5,2] ; \operatorname{RANY}=[0.8,8.5]$ $\mathrm{cm})$. Parameter Combination 2 takes PCN-high $=90$ th; $\operatorname{TRH} 30=6 \mathrm{~cm}$; RANX $=[0.2,2.5]$; and RANY $=$ $[0.8,11.4] \mathrm{cm}$. The number $11.4 \mathrm{~cm}$ corresponds to two daily $\sigma$ in the reference record.

\section{2 | Slope and density corrections}

\section{Effect of slope on the measured signal}

In Fig. S2, snow accumulation takes place over a certain time span (from $t_{1}$ to $t_{2}$ ) and raises the surface. The associated height $(\Delta H)$ is defined vertically (Fierz et al., 2009) like precipitation height in the case of a gauge measurement. On a perfectly flat and horizontal surface (dashed lines), the SR50a would measure $\Delta H$ precisely even at the margins of its measurement cone, since the cosine of half the beam acceptance angle $\left(15^{\circ}\right)$ is $\sim 0.97$.

On a sloped surface, measurements at the inner ( $i$; toward slope) and the outer margin of the beam (o; away from slope) will not be consistent but capture lengths (green in Fig. S2) that differ more substantially from $\Delta H$ (red). From trigonometric relations it follows that - for the shown beam acceptance angle and a slope example of $45^{\circ}-i$ is $18 \%$ less than $\Delta H$ and $o$ is $41 \%$ more than $\Delta H$.

Due to the constantly rough target (ice or snow) surface and the resultant multiple reflection angles, the precise measurement path within the cone (between $i$ and $o$ ) delivering the echo is hard to predict. Hence, as an effective compromise we define the correction factor as average of both percentages. For the example in Fig. S2, the recorded length change must be reduced by $11.5 \%(=(41-18) / 2)$.

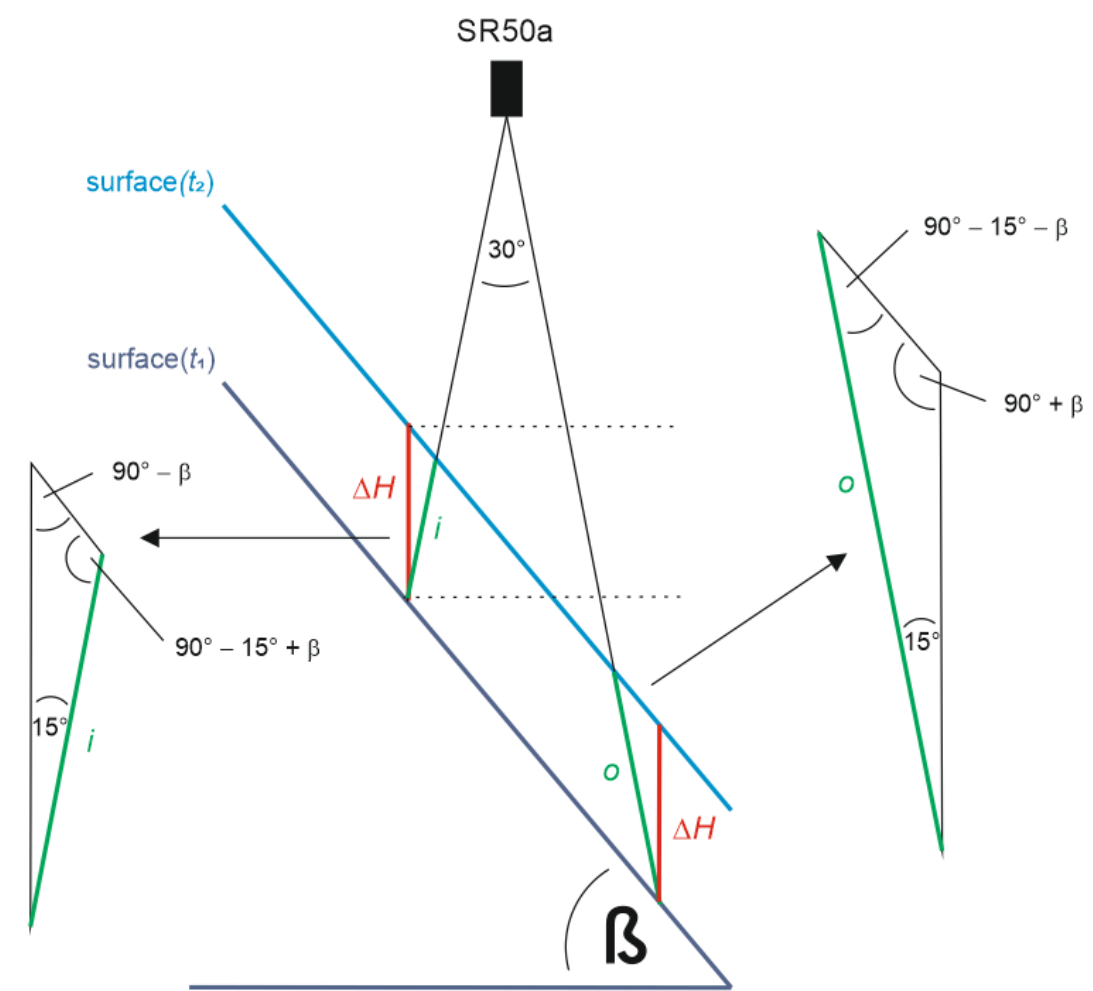

Figure S2: Slope correction. The angle $\beta$ is the local slope. 


\section{Conversion to water equivalent amounts}

The characteristic fresh snow density is hard to determine as its measurement would require our presence on the mountain during many precipitation events, yet expeditions must be scheduled in the dry seasons to facilitate field work. The $\sim 15$ times we got to measure this density nonetheless yields values in the range 150 to slightly above $200 \mathrm{~kg} \mathrm{~m}^{-3}$. This range is a bit lower than earlier estimates that were based on very few samples between 2005 and 2008 (Mölg et al., 2009a).

\section{3 | Total uncertainty estimate}

The total uncertainty results from four sources: (i) instrument uncertainty; (ii) signal extraction algorithm; (iii) slope effect on measurement; and (iv) density importance to convert accumulation to w.e. precipitation. In Table S1 the reference estimate uses Parameter Combination 1 for the algorithm, $18^{\circ}$ and $40^{\circ}$ slope at AWS3 and AWS4, respectively, and $175 \mathrm{~kg} \mathrm{~m}^{-3}$ as fresh snow density. Uncertainty (i) is difficult to quantify. The nominal accuracy of the manufacturer is $0.4 \%$ or $\pm 1 \mathrm{~cm}$ (whichever is greater), yet these values apply to an even and horizontal target surface that is impossible to achieve in our environment (see main text). Thus we neglected source (i) and consider quite large uncertainties instead for the other factors (Table S1).

Table S1: Mean annual accumulation at AWS3 and AWS4 and the associated elevation gradient in different processing and correction settings. The uncertainty is the square root of the sum of squared differences to the reference.

\begin{tabular}{llll}
\hline \multicolumn{1}{c}{ Modification } & $\begin{array}{c}\text { AWS3 } \\
{\left[\mathrm{mm} \mathrm{year}^{-1}\right]}\end{array}$ & $\begin{array}{c}\text { AWS4 } \\
{\left[\mathrm{mm} \mathrm{year}^{-1}\right]}\end{array}$ & $\begin{array}{c}\text { Gradient } \\
{\left[\mathrm{mm} \mathrm{hm}^{-1} \text { year }^{-1}\right]}\end{array}$ \\
\hline Reference & $\mathbf{3 3 4}$ & $\mathbf{6 4 3}$ & $\mathbf{- 1 1 4}$ \\
Parameter Combination 2 & 350 & 716 & -135 \\
Steeper slope (+15\% at both sites) & 334 & 625 & -108 \\
Less slope (-15\% at both sites) & 335 & 655 & -118 \\
Higher fresh snow density $\left(+25 \mathrm{~kg} \mathrm{~m}^{-3}\right)$ & 382 & 734 & -130 \\
Lower fresh snow density $\left(-25 \mathrm{~kg} \mathrm{~m}^{-3}\right)$ & 287 & 551 & -98 \\
\hline Uncertainty & 69 & 151 & 32 \\
\hline
\end{tabular}

\section{References not contained in the main paper}

Fierz, C., Armstrong R. L., Durand Y., Etchevers P., Greene E., McClung D. M., Nishimura K., Satyawali P. K., and Sokratov S. A.: The International Classification for Seasonal Snow on the Ground. IHP-VII Technical Documents in Hydrology N83, IACS Contribution N²1, UNESCO-IHP, Paris, 2009. 

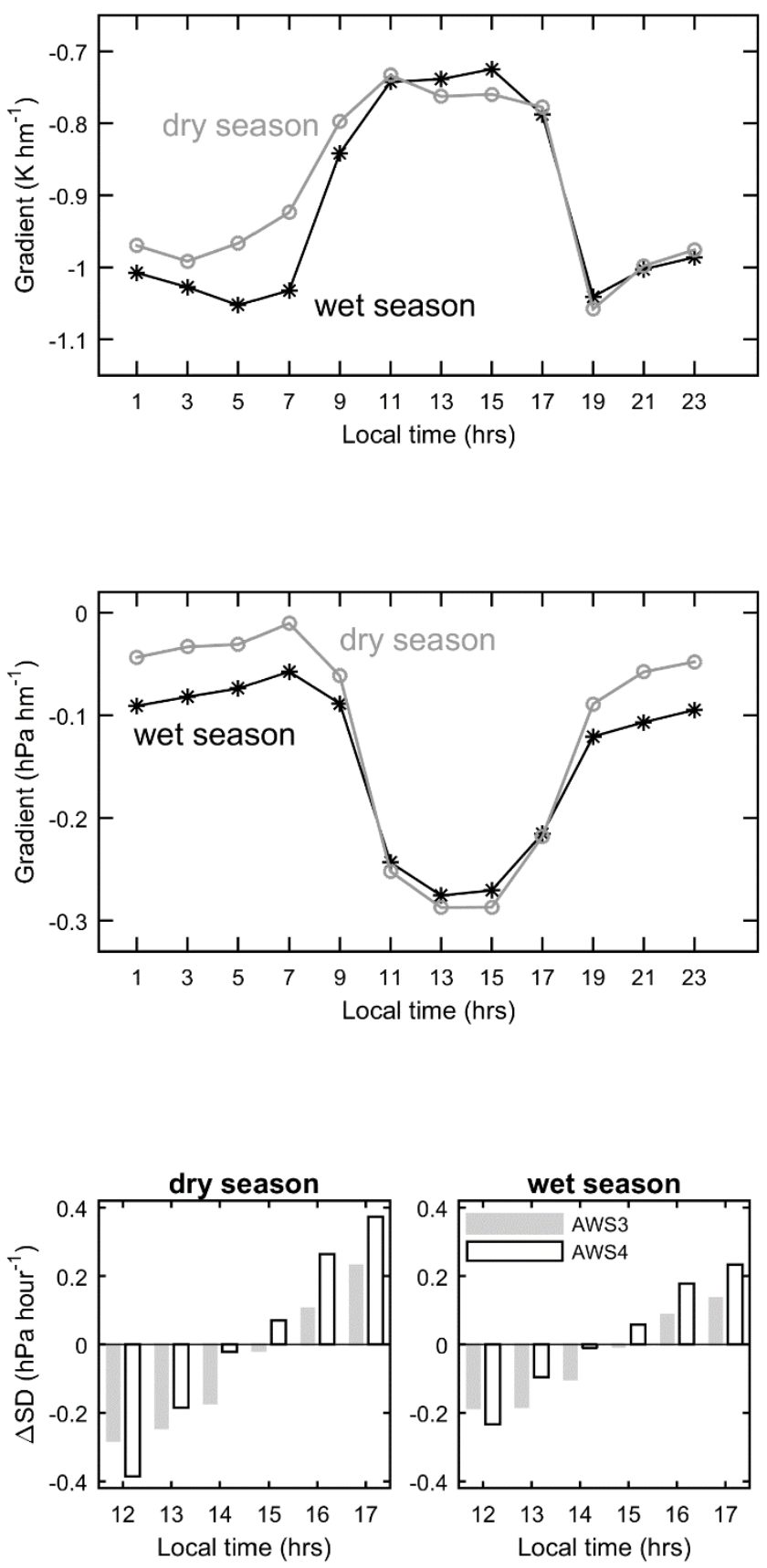

Figure S3: Mean diurnal cycle of the $T$ gradient for the climatological dry (JF, JJAS) and wet (MAM, OND) seasons in gray and black, respectively, between 8 October 2009 and 30 September 2013 in the atmospheric model's summit zone. The analysis is based on the model output from Collier et al. (2018).

Figure S4: Mean diurnal cycle of the water vapor pressure gradient for the climatological dry (JF, JJAS) and wet (MAM, OND) seasons in gray and black, respectively, between 8 October 2009 and 30 September 2013 in the atmospheric model's summit zone. The analysis is based on the model output from Collier et al. (2018).

Figure S5: Mean hourly changes of the water vapor pressure saturation deficit (SD) for the climatological dry (JF, JJAS) and wet (MAM, OND) seasons between 8 October 2009 and 30 September 2013 at AWS3 (gray) and AWS4 (white) during the afternoon. 